\title{
Bibliometric analysis of medical journals included in the Mexican Science and Technology Journals Classification System
}

\author{
Aldo Barajas-Ochoa, ${ }^{1 *}$ Zalathiel Barajas-Ochoa ${ }^{2}$ and César Ramos-Remus ${ }^{3}$ \\ ${ }^{1}$ Rutgers New Jersey Medical School, Department of Medicine, New Jersey, United States; ${ }^{2}$ Instituto Mexicano del Seguro Social, Hospital Regional de \\ Especialidades 25, Monterrey, Nuevo León, Mexico; ${ }^{3}$ Unidad de Investigación en Enfermedades Crónico-Degenerativas, Guadalajara, Jalisco, Mexico
}

\begin{abstract}
Introduction: CONACYT's Classification System of Mexican Science and Technology Journals (SCRMCYT) includes the area of medicine and health sciences (M\&HS). Objective: A bibliometric analysis of M\&HS journals listed in SCRMCYT in 2018 was performed. Method: Twelve characteristics related to indexation in the Web of Science Core Collection (WoSCC), Scopus, and PubMed databases were analyzed. Indexed journals were analyzed on whether they had recent indexed publications (2017 and 2018). Indexed journals' 50 most-cited articles in WoSCC and Scopus were analyzed. Results: Of the 35 M\&HS journals included in the 2018 SCRMCYT list, 31 (89 \%) were indexed in Scopus (22 with indexed publications in 2017; 18 in 2018), 17 (49\%) in PubMed (10 with indexed publications in 2017 and 2018), and 12 (34\%) in WoSCC (12 with indexed publications in 2017; 8 in 2018). The 50 most-cited articles had been published only in 4 journals indexed in WoSCC and 5 in Scopus; 60 $\%$ were review articles. Conclusions: Approximately half the 2018 SCRMCYT M\&HS journals lack publications indexed in 2018; this suggests that national and international relevance of these journals can be improved.
\end{abstract}

KEY WORDS: Mexico. Bibliometrics. Bibliographic databases. Serial publications.

\section{Introduction}

In scientific research, the publication of articles in scientific journals that have a peer review system represents a contribution to scientific knowledge that is on top of other forms of scientific production. The scientific journals of a country are an important tool for the diffusion and divulgation of science generated in the nation. In Mexico, the National Council of Science and Technology (CONACYT - Consejo Nacional de Ciencia y Tecnología) evaluates scientific journals through the Mexican Science and Technology Journals Classification System (SCRMCYT - Sistema de Clasificación de Revistas Mexicanas de Ciencia y Tecnología). The SCRMCYT is "a public policy instrument that, through selective registration and periodic evaluation of scientific journals published in electronic format in Mexico, seeks to raise their quality, visibility and impact and, thus, encourage diffusion and divulgation of science and technology generated in the country". To join the SCRMCYT, the electronic versions of Mexican scientific journals (those with Mexican affiliation international standard serial number [ISSN]) are assessed by international specialists in scientific publishing. There are two ways for inclusion into the System: if the journal is indexed in the multidisciplinary international Web of Science (WoS) (Sciences Citation In$\mathrm{dex}^{\circledR}$, Social Sciences Citation Index ${ }^{\circledR}$ and Arts \& Humanities Citation Index ${ }^{\circledR}$ collections) or Scopus databases and has citation indicators, it is immediately included; if the journal is not indexed in these databases, it must be subjected to a competition process to be admitted, and it is therefore assessed according to SCRMCYT specific criteria. ${ }^{1}$

Bibliometric analysis is the use of statistical methods to analyze a body of literature. ${ }^{2,3}$ Bibliometric
Gac Med Mex. 2019;155:237-244

Contents available at PubMed www.gacetamedicademexico.com 
analysis includes identifying the databases where the scientific journals are indexed, as well as quantifying the number of publications or citations of journals and identifying their most cited articles; in addition, its results can be used to identify the recognition a journal has in the scientific community. Bibliometric analyses have been made in multiple medical topics and specialties, ${ }^{4-7}$ but an independent bibliometric analysis of SCRMCYT medicine and health sciences journals characteristics' has not been performed. The purpose of this study was to perform a bibliometric analysis of journals in the area of medicine and health sciences of the SCRMCYT 2018 list.

\section{Method}

A bibliometric analysis of the journals included in the SCRMCYT 2018 area of medicine and health sciences (category III) was carried out, in accordance with the official list published by CONACYT National Consortium of Scientific and Technological Information Resources (CONRICYT - Consorcio Nacional de Recursos de Información Científica y Tecnológica). ${ }^{8,9}$ From the official list, the SCRMCYT category (descending order of relevance: Q1, Q2, Q3, Q4, "international competence", "national competence", "in consolidation process" and "in development") ${ }^{8}$ was obtained, as well as the impact factor (IF) and total number of citations at WoS Journal Citation Report and Scopus SCImago Journal \& Country Rank (SJR). ${ }^{8,9}$

The inclusion of journals in the area of medicine and health sciences from the SCRMCYT 2018 list in the WoS Core Collection (WoSCC, only indexes from 1980 to the present period), Scopus (all years) and PubMed databases (all years) was analyzed. From WoSCC and Scopus, the number of publications per journal, the indexing years, the number of citations of the 50 most cited articles per journal and total number of citations per journal were obtained (the latter was only available in WoSCC). The name of the journal was searched (two searches, with and without diacritical marks) in the "source title" (Scopus) and "publication name" (WoSCC) fields. WoSCC was used because it includes the databases used by SCRMCYT (Science Citation Index, Social Sciences Citation Index and Arts \& Humanities Citations Index), but only considers those journals that are indexed cover-to-cover. In PubMed, the number of publications indexed per journal and their years of indexing were obtained.
Whether the journals indexed in the databases had recently-indexed publications (years 2017 and 2018) was analyzed. For each database, category Q1 to Q4 indexed journals (IP, indexed publication), journals with at least one indexed publication that would have been published after 2016 (IP $\geq 2017$ ) and journals with at least one 2018 publication (IP-2018) were quantified. For each database, the difference in proportions between having at least one indexed publication against having at least one indexed publication in 2017 (i.e., IP versus IP $\geq 2017$ ), and in 2018 (i.e., IP versus IP-2018) was calculated.

The correlation of the SCRMCYT category with the IF and with SJR was calculated (Pearson's r); the cases with missing data were not included in the analysis.

A sub-analysis of the characteristics of the 50 most cited SCRMCYT journals' articles included in Scopus and WoSCC was carried out, for which purpose the number of citations, journal of origin, first author, type of article (original article, review, others) and publication year were obtained.

The search in the databases was carried out on September 24, 2018. The ethics committee of the Unidad de Investigación en Enfermedades Crónico-Degenerativas reviewed and approved the research protocol, without there being any ethical consideration due to the nature of the studied information.

\section{Results}

Only 35 medicine and health sciences journals were included in the SCRMCYT 2018 list. Only Archives of Medical Research and Annals of Hepatology were classified in the categories of the highest academic recognition (Q1 and Q2, respectively). Most journals were category Q4 (60\%), and five journals (14\%) were included in the "international competence", "national competence" and "on development" categories (Table 1).

The number and proportion of SCRMCYT indexed journals was $31(89 \%)$ in Scopus, $17(49 \%)$ in PubMed, and 12 (34\%) in WoSCC (Table 1). When only category Q1 to Q4 journals were considered, $30(100 \%)$ had indexed publications in Scopus, 17 $(57 \%)$ in PubMed and 12 (40\%) in WoSCC. Only eight journals (one category Q1, one Q2, five Q3, and one Q4) were indexed in all three databases; the areas of knowledge of these journals were basic and clinical research, public health, general medicine, general surgery and the cardiology, gastroenterology and 


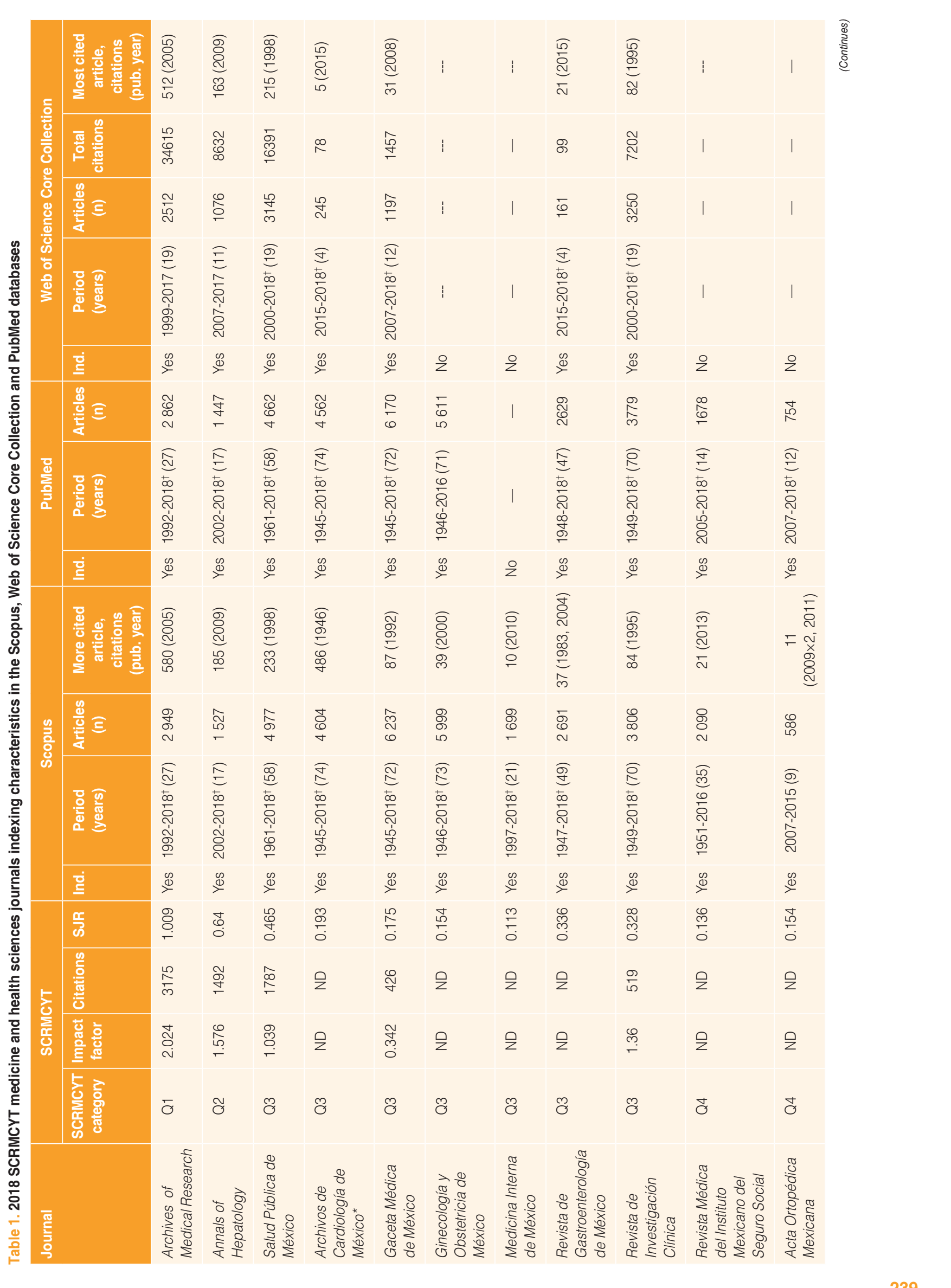




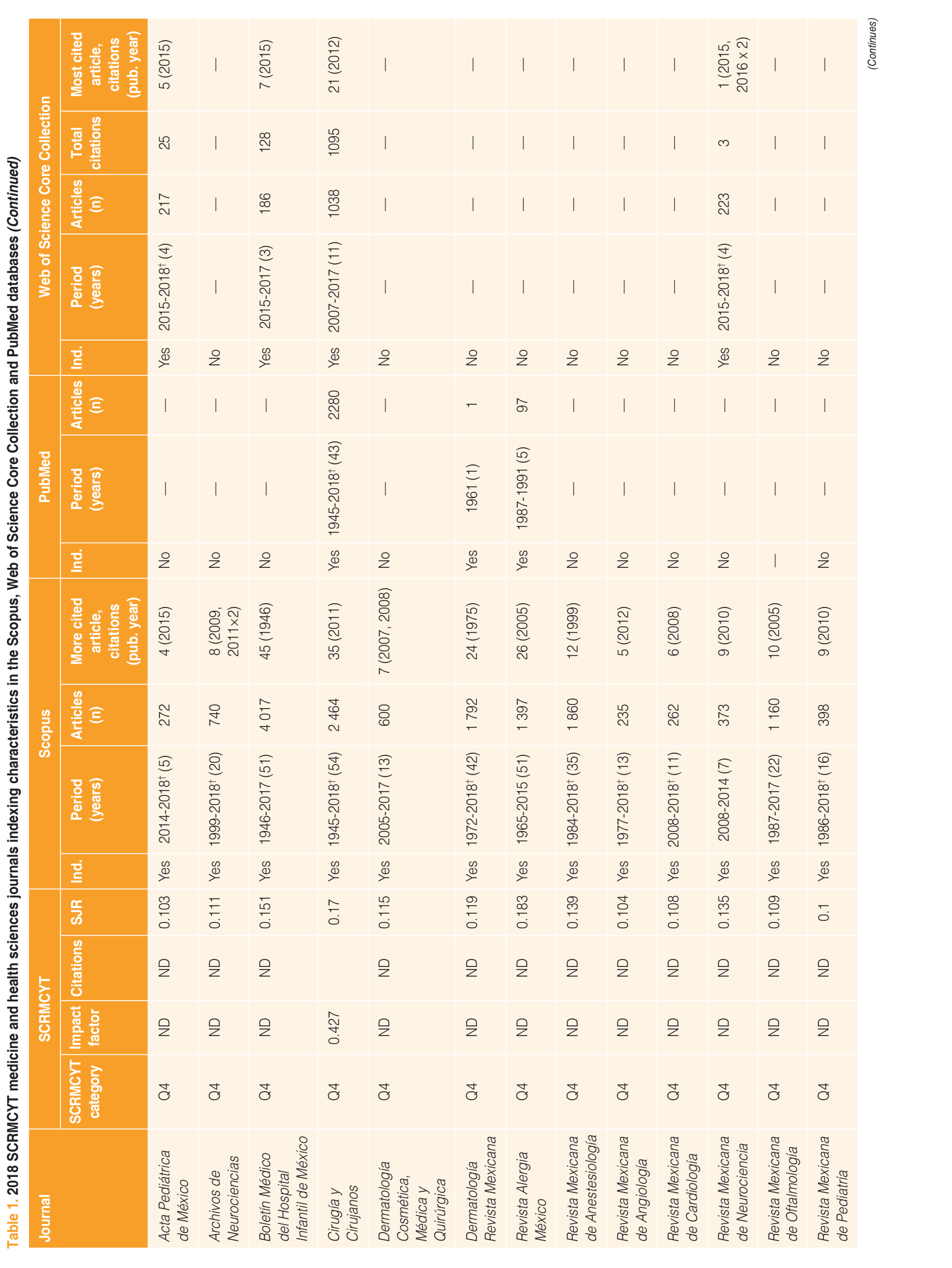




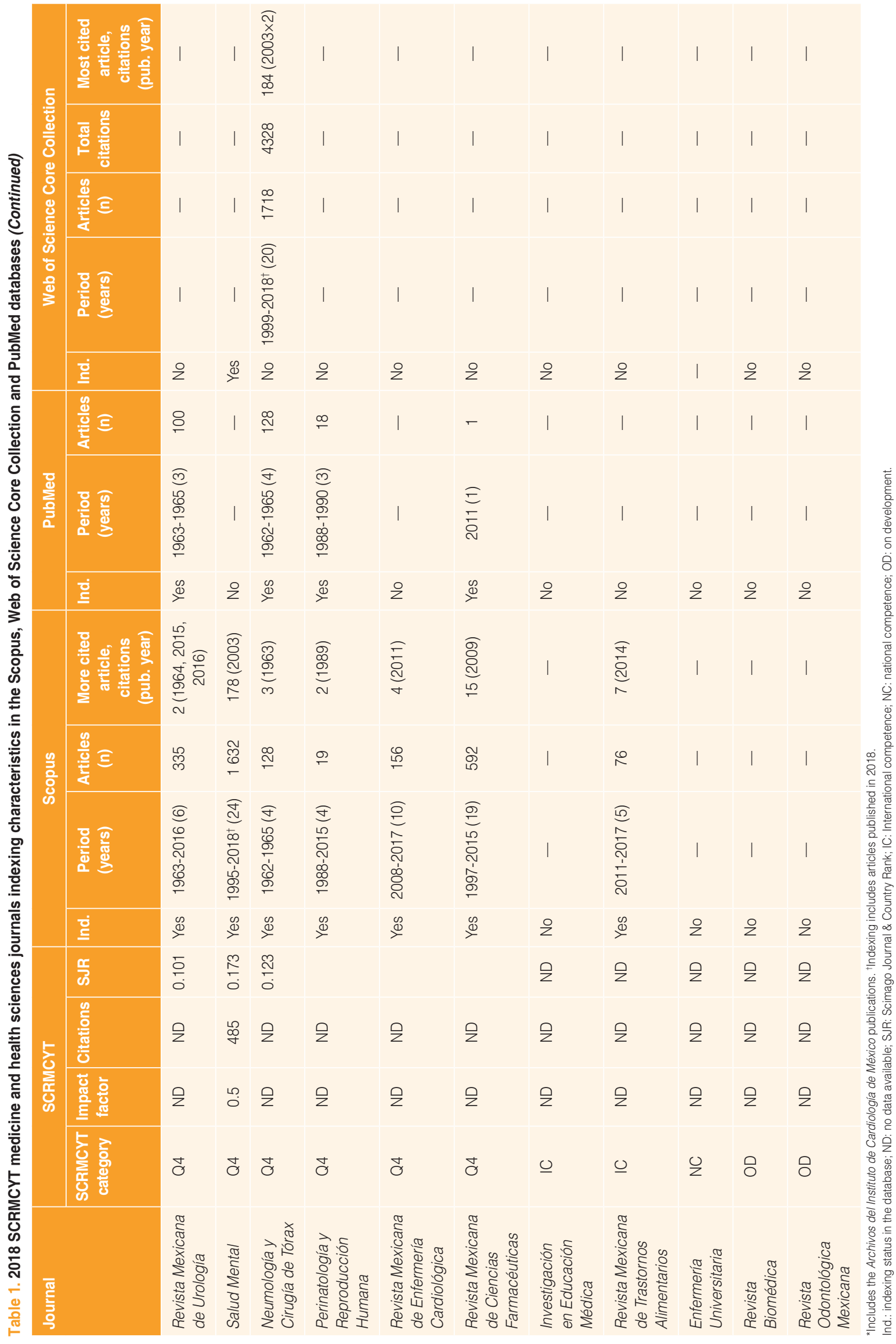


hepatology subspecialties. Most journals with SCRMCYT categories Q1 to Q4 covering medical subspecialties were in Scopus and in one of the other two databases. However, the Medicina Interna de México, Archivos de Neurociencias, Dermatología Cosmética, Medica y Quirúrgica, Revista Mexicana de Anestesiología, Revista Mexicana de Angiología, Revista Mexicana de Cardiología, Revista Mexicana de Oftalmología and Revista Mexicana de Pediatría journals were only found in Scopus. An error was found in the SCRMCYT category assigned to Revista Mexicana de Trastornos Alimentarios, since it was categorized as "international competence" despite being indexed in Scopus and having citation indicators for the 2011-2017 period.

Table 2 shows the statistics for journal indexing in the different databases. The difference in the proportion of IP versus IP $\geq 2017$ was $27 \%$ in Scopus, $24 \%$ in PubMed and 0 in WoSCC. The differences for IP versus IP-2018 were $40 \%$ in Scopus, $24 \%$ in PubMed and $13 \%$ in WoSCC. The most extreme case of non-current indexing was that of the Neumología $y$ Cirugía de Tórax journal, which was only indexed in Scopus and PubMed in the 1962-1965 period.

The IF was only reported in seven $(20 \%)$ of the SCRMCYT journals, while SJR was in $30(86 \%)$ journals. The correlation between IF and the SCRMCYT category $(r[5]=0.88, p<0.01)$ and SJR and the SCRMCYT category $(r[28]=0.89, p<0.001)$ showed that the largest the IF and SJR, the highest the SCRMCYT category.

Regarding SCRMCYT journals 50 most cited articles in the databases, Scopus showed more citations than WoSCC (Table 3). The databases showed high consistency, with $42(84 \%)$ articles included in both listings. Ten of these 42 articles had the same position in both lists and most of the rest had similar positions: 30 (Scopus) and 29 (WoSCC) of these articles were review articles and had more citations than the original articles. The two most cited articles were the same in both lists. The review article "Resistance to antibiotics: are we in the post-antibiotic era?", written by Alanis in 2005 and published in Archives of Medical Research, ${ }^{10}$ was the most cited article, with 580 and 512 citations in Scopus and WoSCC, respectively. The second most cited article, with 551 and 507 citations in Scopus and WoSCC, respectively, was "The global emergence/resurgence of arboviral diseases as public health problems", by Gubler et al., published in Archives of Medical Research in 2002." Both these articles were the only ones with more than 500 citations.
Table 2. Indexing in the databases of the 30 SCRMCYT 2018 category Q1 to Q4 medicine and health sciences journals

\begin{tabular}{|c|c|c|c|c|c|c|}
\hline \multirow[t]{2}{*}{ Database } & \multicolumn{2}{|c|}{$\begin{array}{c}\text { IP: } \\
\text { Indexed } \\
\text { journals }\end{array}$} & \multicolumn{2}{|c|}{$\begin{array}{c}\text { IP } \geq 2017 \text { : Journals } \\
\text { with at least one } \\
\text { publication after } \\
2016\end{array}$} & \multicolumn{2}{|c|}{$\begin{array}{l}\text { IP-2018: Journals } \\
\text { with at least one } \\
2018 \text { indexed } \\
\text { publication }\end{array}$} \\
\hline & $\mathrm{n}$ & $\% *$ & $\mathrm{n}$ & $\% *$ & $\mathrm{n}$ & $\%{ }^{*}$ \\
\hline Scopus & 30 & 100 & 22 & 73 & 18 & 60 \\
\hline PubMed & 17 & 57 & 10 & 33 & 10 & 33 \\
\hline WoSCC & 12 & 40 & 12 & 40 & 8 & 27 \\
\hline
\end{tabular}

*Percentages rounded to the nearest integer.

WoSCC: Web of Science Core Collection.

Table 3. Characteristics of the 50 most cited articles of SCRMCYT 2018 medical and health sciences journals

\begin{tabular}{|c|c|c|}
\hline & $\begin{array}{c}\text { Scopus } \\
\text { (n) }\end{array}$ & $\begin{array}{c}\text { Woscc } \\
\text { (n) }\end{array}$ \\
\hline $\begin{array}{l}\text { Number of citations } \\
\text { Most cited article } \\
\text { Article in position } 13 \\
\text { Article in position } 25 \\
\text { Article in position } 38 \\
\text { Article in position } 50\end{array}$ & $\begin{array}{l}8618 \\
580 \\
185 \\
128 \\
111 \\
100\end{array}$ & $\begin{array}{c}7388 \\
512 \\
173 \\
116 \\
93 \\
84\end{array}$ \\
\hline $\begin{array}{l}\text { Journal } \\
\text { Archives of Medical Research } \\
\text { Annals of Hepatology } \\
\text { Salud Pública de México } \\
\text { Salud Mental } \\
\text { Archivos de Instituto de Cardiología } \\
\text { de México }\end{array}$ & $\begin{array}{c}36 \\
7 \\
5 \\
1 \\
1\end{array}$ & $\begin{array}{l}36 \\
5 \\
6 \\
3 \\
0\end{array}$ \\
\hline $\begin{array}{l}\text { Type of Article } \\
\text { Review } \\
\text { Original article } \\
\text { Conference article }\end{array}$ & $\begin{array}{c}30 \\
19 \\
1\end{array}$ & $\begin{array}{c}29 \\
20 \\
1\end{array}$ \\
\hline $\begin{array}{l}\text { Publication Period } \\
\text { Prior to } 1990 \\
1991-2000 \\
2001-2010 \\
2011-2018\end{array}$ & $\begin{array}{c}1 \\
6 \\
39 \\
4\end{array}$ & $\begin{array}{c}0 \\
7 \\
38 \\
5\end{array}$ \\
\hline
\end{tabular}

The third most cited article in Scopus, indexed as an original article with 486 citations and entitled "The mathematical formulation of the problem of conduction of impulses in a network of connected excitable elements, specifically in cardiac muscle", was published in 1946 in Archivos del Instittuto de Cardiología de México $^{12}$ (today Archivos de Cardiología de México), by Wiener et al.; this article did not appear on WoSCC due to the database inclusion period (1980-2018). The number and proportion of articles with $\geq 300$ citations, 200-299 citations, 100-199 citations and < 100 citations was three (6\%), seven (14\%), $40(80 \%)$ and 0 in Scopus, and two (4\%), six (12\%), 27 (54\%) and 
$15(30 \%)$ in WoSCC, respectively (data not shown, available upon request). The journal with more articles included in the 50 most cited articles was Archives of Medical Research (36 [72\%] articles per database); review articles accounted for $64 \%$ (Scopus) and $66 \%$ (WoSCC) of its articles. The next two journals with more articles in the 50 most cited were Annals of Hepatology and Salud Pública de México.

When analyzing the most cited article of each one of the SCRMCYT journals, only seven journals $(23 \%)$ in Scopus and five (17\%) in WoSCC were found to have more than 50 citations in their most cited article.

\section{Discussion}

This article presents a bibliometric analysis of the characteristics of journals in the area of medicine and health sciences included the 2018 SCRMCYT list. The results inform on indexing, citations and relevance of Mexican scientific journals from that area, as well as the characteristics of the most cited articles of these journals.

This analysis shows three main findings:

- First, Scopus was found to index more SCRMCYT articles and journals of the area of medicine and health sciences than PubMed and WoSCC (and PubMed more than WoSCC); in addition, Scopus reported more citations for all analyzed articles than WoSCC. These findings agree with previous studies, which have shown that Scopus and WoS have a high correlation in the number of articles, and in the number of citations by country, that bibliometric analyses can be performed in all three databases and that Scopus has broader coverage than WoS and PubMed. ${ }^{13-17}$

The SCRMCYT aims to raise visibility and impact of scientific journals published in the country. ${ }^{1}$ Indexing a journal in an international multidisciplinary database such as WoS or Scopus influences its dissemination and impact. ${ }^{18}$ This indexing is the characteristic that positions a Mexican scientific journal in SCRMCYT highest impact categories (Q1 to Q4); ${ }^{1}$ however, when analyzing whether the Q1 to Q4 category journals had recently indexed publications (years 2017 and 2018), the indexing proportion decreased between 13 and $40 \%$. That is, SCRMCYT's practice of categorizing the journals within its most important categories just for having an article indexed in Scopus or WoS, regardless of whether they are recently indexed publications does not reflect journals' real impact and visibility (for example, the last publication indexed from a Q4 journal was in 1965).
- The second finding was that the SCRMCYT category has a high correlation with IF and SJR, although the SCRMCYT did not report the IF for all journals. This shows consistency between the two values that are commonly used to reflect the relevance of journals and the SCRMCYT categorization. It should be noted that SCRMCYT categorization errors were detected.

- The third finding corresponds to journal citations. Three journals dominated in the 50 most cited articles (Archives of Medical Research, which is a scientific journal of the Instituto Mexicano del Seguro Social; Annals of Hepatology, which is the scientific journal of the Asociación Mexicana de Hepatología, Asociación Latinoamericada para el Estudio del Hígado and of the Asociación Canadiense para el Estudio del Hígado, and Salud Pública de México, of the National Institute Public Health); most these articles were review articles published in 2001-2010. Review articles are expected to have more citations than original articles. ${ }^{2}$ In addition, in less than one quarter of the analyzed journals, the most cited article had more than 50 citations. This reflects the opportunities for improvement of most of these SCRMCYT medicine and health sciences journals.

The strengths of this study include that current information from the international databases Scopus, WoSCC and PubMed was used, which are three of the more reliable databases for bibliometric analyses. ${ }^{15-17,19}$ Multiple aspects about the relevance of the country's medical scientific journals were analyzed, including their indexation in international databases, years of indexation, number of indexed articles, number of citations, the analysis of the most cited articles during the periods with available records, and the analysis of the each journal's most cited articles. However, there are limitations that should be considered. The WoSCC database was used, which only includes the 1980-to-present period, although this database was selected for being the most selective, since it only registers journals of the highest quality..$^{15,20}$ In addition, it was not possible to obtain the number of citations per journal in Scopus, and the impact factor was not available for all the journals reported by the SCRMCYT.

\section{Conclusions}

The SCRMCYT represents an effort to promote quality, visibility and national and international impact 
of the medicine and health science journals of the country. However, a significant percentage of journals included in the SCRMCYT 2018 list have no current indexing even in the analyzed international databases, and most journals on the list have little international impact and few citations. It is important to maintain and strengthen initiatives like this and create others that allow addressing different areas of opportunity to promote research in medicine and health sciences in Mexico.

\section{References}

1. Sistema de Clasificación de Revistas Mexicanas de Ciencia y Tecnología [sitio web]. México: Conacyt; 2018.

2. Bibliometrics and Citation Analysis [sitio web]. EE. UU.: University of Wisconsin-Madison Libraries; 2018.

3. Ellegaard $\mathrm{O}$, Wallin JA. The bibliometric analysis of scholarly production: how great is the impact? Scientometrics. 2015;105:1809-1831.

4. Chang MT, Schwam ZG, Schutt CA, Kamen EM, Paskhover B. The 50 most cited articles in facial plastic surgery. Aesthetic Plast Surg. 2017; 41:1202-1207.

5. Tang X, Gong W, Yuan F, Li R, Han X, Huang S, et al. Top-cited articles in digestive system disease from 1950 to 2013. J Gastroenterol Hepatol. 2016;31:107-111.

6. Tao T, Zhao X, Lou J, Bo L, Wang F, Li J, et al. The top cited clinical research articles on sepsis: a bibliometric analysis. Crit Care. 2012;16:R110.
7. Gu W, Yuan Y, Yang H, Qi G, Jin X, Yan J. A bibliometric analysis of the 100 most influential papers on COPD. Int J Chron Obstruct Pulmon Dis. 2015;10:667-676.

8. Consejo Nacional de Ciencia y Tecnología [sitio web]. Sistema de Clasificación de Revistas Mexicanas de Ciencia y Tecnología Revistas de Medicina y Ciencias de la Salud. México: Conacyt; 2018.

9. Consorcio Nacional de Recursos de Información Científica y Tecnológica [sitio web]. Listado de revistas del Sistema de Clasificación de Revistas Mexicanas de Ciencia y Tecnología. México: Conacyt; 2018.

10. Alanis AJ. Resistance to antibiotics: are we in the post-antibiotic era? Arch Med Res. 2005;36:697-705.

11. Gluber DJ. The global emergence/resurgence of arboviral diseases as public health problems. Arch Med Res. 2002;33:330-342.

12. Wiener N, Rosenblueth $A$. The mathematical formulation of the problem of conduction of impulses in a network of connected excitable elements, specifically in cardiac muscle. Arch Inst Cardiol Mex. 1946;16:205-265.

13. Archambault É, Campbell D, Gingras Y, Lariviere V. Comparing bibliometric statistics obtained from the Web of Science and Scopus. J Assoc Inf Sci Technol. 2009;60:1320-1326.

14. Mongeon P, Paul-Hus A. The journal coverage of Web of Science and Scopus: a comparative analysis. Scientometrics. 2016;106:213-228.

15. Ellegaard $\mathrm{O}$, Wallin JA. The bibliometric analysis of scholarly production: how great is the impact? Scientometrics. 2015;105:1809-1831.

16. Kokol P, Vošner HB. Discrepancies among Scopus, Web of Science, and PubMed coverage of funding information in medical journal articles. J Med Libr Assoc. 2018;106:81-86.

17. Falagas ME, Pitsouni El, Malietzis GA, Pappas G. Comparison of PubMed, Scopus, Web of Science, and Google Scholar: strengths and weaknesses. FASEB J. 2008;22:338-42.

18. Akhigbe RE. Scientific journals: indexation and impact factor. Lung India. 2012;29:300-301.

19. Michigan State University? [sitio web]. So which is better: PubMed, Web of Science, or Google Scholar. EE. UU.: Michigan State University; 2019.

20. Clarivate Analytics [sitio web]. Web of Science Core Collection. EE. UU.: Clarivate Analytics; 2019. 